\title{
RUCOVSKY, Martín Adrian de Mauro. \\ Cuerpos en escena. Materialidad y \\ cuerpo sexuado en Judith Butler y \\ Paul B. Preciado. 216 f. Barcelona/ \\ Madrid: Editorial Egales, 2016.
}

\author{
Bryan Axt \\ Graduação em Filosofia (2018). Pontifícia Universidade Católica do Paraná - PUC-PR. Escola de \\ Educação e Humanidades, Departamento de Filosofia. Curitiba, PR - Brasil.
}

A recente obra publicada por Martín Rucovsky, Cuerpos en escena, ainda não traduzida ao português brasileiro, reúne os resultados de uma pesquisa extensa e muito precisa ao redor das caixas de ferramentas ${ }^{1}$ de Judith Butler e Paul B. Preciado. Inspirado em Bertolt Brecht e nas artes cênicas, Rucovsky organiza este ensaio a partir de uma diferente proposta metodológica, apresentando-nos algo que excede limites, podendo ser caracterizado também como uma parábola, rapsódia ou um vaudeville (2016, p. 36). Parte de sua proposta, Cuerpos en escena é um livro que pode ser lido de modo linear, observando-se um começo, meio e fim, mas, também, pode ser lido sem uma ordem específica, ficando a critério de quem o lê.

Ao longo do livro o autor utiliza da noção de "puesta en escena" [posta em cena/colocar em cena/encenação], que se refere à organização ou direção de um espetáculo, para organizar quatro atos que integram um teatro de operações ${ }^{2}$, no qual os pensamentos vanguardistas de Butler e Preciado são analisados autonomamente, isto é, tomando

\footnotetext{
${ }^{1}$ Importante na construção ensaística de Rucovsky, esta noção está presente também nas obras de Foucault, Deleuze, Butler e Preciado. Por "caixas de ferramentas" deve-se entender não apenas um sistema, mas um conjunto de instrumentos disponíveis para serem utilizados em uma "mesa de operações".

${ }^{2}$ Rucovsky dedica a sua introdução para além da apresentação das teorias que serão investigadas, pois esclarece também a sua influência das artes cênicas, mais especificamente da noção de "teatro de operações" que, tendo algo em comum com as "salas de operações" e "mesas de operações", faz referência às modernas instalações em que os corpos humanos e não-humanos passam por um sem-fim de intervenções, dissecções e reconstruções por médicos, estudantes e até mesmo por seus espectadores, que, coniventes, são também responsáveis por estes espaços estéreis, redutos tecnocientíficos de experimentações com o corpo e com a linguagem, os principais "pacientes" levados aos limites das práticas de inscrições discursivas-carnais. Ressignificando esta noção de modo a romper com este dispositivo-imperativo de correção anatomopolítica, a abstrata "mesa de operações" se torna complementar à noção de "caixa de ferramentas", nos oferecendo meios de realizar operações conceituais complexas, relações entre diversos conceitos, autoras e autores, acontecimentos etc. como uma estratégia metodológica.
} 
os cuidados necessários a cada teoria individualmente para, enfim, confrontá-las a partir de suas interseções, evidenciando suas aproximações e distanciamentos.

O autor tensiona ambos os corpora teóricos a partir de um contexto local, da interpretação e da produção de conhecimentos por autoras e autores latino-americanos, deslocando a centralidade das epistemologias norte-americana e europeia, oferecendo-nos uma crítica, inclusive, às teorias butleriana e preciadiana, por falarem a partir do norte global. Para citar algumas autoras e autores, será possível encontrar influências de Aníbal Quijano, Blas Radi, Eduardo Grüner, Eduardo Mattio, Emmanuel Theumer, Ernesto Laclau, Mabel A. Campagnoli, Mauro Cabral, María Eugenia del Zotto, María L. Femenías, Mauro Teodoro Ramírez, Natalia Martínez Prado, Néstor Perlongher, Paula Sibilia, Paula Viturro, Virginia Cano e entre outras e outros.

Graduado e doutorando em Filosofia pela Universidad Nacional de Córdoba, Martín Rucovsky atua em uma área de conhecimento que é tão suspeita quanto as que Butler e Preciado criticam em suas obras. Em um ensaio em que se encontra uma genealogia das produções discursivas dos saberes-Verdade, a Filosofia passa por sua própria averiguação, subvertendo o "canônico" de dentro para fora, fazendo também da academia um espaço de resistência e ferramenta para a luta de todos os sujeitos subalternizados e corpos abjetos.

Pode-se dizer que há dois grandes propósitos girando em torno da investigação da teoria de Butler e Preciado. O primeiro trata de esclarecer a falsa dicotomia entre o discurso e a matéria, entre materialidade e significatividade, entre fala e corpo, mas acerca também do alcance ontológico e político dessa falsa dicotomia no presente, que se estende e interfere em nossas vidas, em nossa constituição como sujeitos, em nossos afetos, desejos, sexualidades e corporalidades etc. O segundo aponta para a diferença entre as caixas de ferramentas que operam a teoria de Butler e Preciado, de modo a evidenciar que as teorias se aproximam mais do que se afastam e que, se se afastam, o fazem por escolhas metodológicas. Desse modo, Rucovsky nos possibilita a leitura em ao menos dois níveis de complexidade, conseguindo manter uma linguagem clara e compreensível, mas também conseguindo verticalizar estas mesmas questões. Assim, reúne uma multiplicidade de produções anteriores à sua, sintetizando um debate complexo e amplo, inserindo-se entre as autoras e autores que atualmente contribuem com o aprofundamento dos estudos de gênero, queer/ cuir, estudos decoloniais, da filosofia política, epistemologia e ontopolítica.

Para isso, em um primeiro momento, Rucovsky se dedica a analisar o plano de fundo da teoria da performatividade de gênero, de Judith Butler, recorrendo, além das obras, aos artigos publicados por Butler ao longo de sua teorização. Desse modo, nos dois primeiros atos, "Teatro y drama en Judith Butler" e "Escritos con el cuerpo o de qué están hechos los cuerpos", Rucovsky remonta os passos de Butler em sua construção argumentativa, partindo das análises da filósofa acerca do sujeito e do assujeitamento, de sua crítica à fenomenologia de Sartre que, inevitavelmente, influencia Simone de Beauvoir, que expande a extensão conceitual da fenomenologia sartreana ao sexo e ao gênero. A partir desses textos, Butler pôde demonstrar como, em sua perspectiva, não há um "ator" por trás de um "ato", sendo o ator mesmo construído ou fabricado na medida em que realiza este ato, já dialogando com teorias como a de Bruce Wilshire, dos estudos antropológicos, psicanalíticos e a teoria dos atos de fala, de John Austin (relido por Jacques Derrida). De modo singular, Butler aponta para uma iterabilidade e citacionalidade de gênero que só poderia significar que o gênero está além de uma determinação biológica e essencial, mas permeado por disputas de poder que são históricas e culturais, portanto, o gênero se dá de modo performativo.

Estas relações e disputas de poder, veiculadas por práticas discursivas, produzem um efeito pré-discursivo para o sexo, fixando efeitos de verdade ao sexo e ao gênero. Como um aparato de construção social do gênero e de inteligibilidade cultural, o sexo pertence ao mesmo âmbito de realidade que o gênero, isto é, são ambos elaborações 
culturais que possuem a mesma primazia ontológica (2016, p. 85). Porém, Judith Butler é criticada após a publicação de Gender Trouble por, supostamente, manter as suas investigações em uma dimensão discursiva da produção do sexo-gênero, desfazendo-se prematuramente do corpo, caracterizando então um "construtivismo discursivo de gênero". No entanto, Butler está interessada pelas normas que regulam os processos de materialização do corpo, dos significados que estes processos fazem circular e, principalmente, leva em consideração estas críticas para, com a publicação de Bodies That Matter, retornar à problemática da relação entre linguagem e matéria, reconfigurando a própria noção de performatividade, de modo a dar conta dos processos de produção da realidade material dos corpos.

Consideramos importante destacar que, ao retornar a estes problemas, Rucovsky aponta para a omissão da noção de quiasma por parte de Preciado, uma noçãochave que Butler tomou emprestada de Maurice Merleau-Ponty. A partir da noção de quiasma, Butler argumenta que, não havendo um referente puro para a matéria que a separe, no limite, da linguagem, então a relação entre o discurso e a matéria é paradoxal, pois produz um efeito dissimulado de materialidade prévia. Assim, os discursos necessitam de um suporte material (auditivo, fônico, visual, gráfico etc.) para que sejam veiculados. A noção de quiasma, no entanto, não implica uma redução entre discurso e corpo, sem ocorrer, necessariamente, uma identificação, nem uma radical oposição ou diferença (2016, p. 111).

É a partir daqui, da transição entre os primeiros atos e o terceiro ato, Mutilaciones, prótesis y cíborgs en Paul B. Preciado, que Rucovsky passará a analisar autonomamente a teoria preciadiana. Com isso, analisa a crítica de Preciado à teoria performativa de gênero, assim como a sua tese, em que a plasticidade e a arquitetura externa aos corpos se encontram em uma escala biomolecular, os fabricando a partir da tecnociência farmacopornográfica e de seus pilares de sustentação: a indústria farmacêutica e a indústria pornográfica.

Quando Preciado omite a leitura quiasmática da materialidade dos corpos, omite também o suporte material que o discurso necessita para se veicular, o que é precisamente aquilo que teoriza após criticar Butler. É interessante lembrar que Preciado define a sua noção de farmacopornografia a partir de uma relação, que não necessariamente é de identificação nem de radical diferença, com a farmacologia (enquanto área de produção de saberes), as indústrias farmacêuticas (enquanto linhas de produção biomolecular em escala industrial) e a pornografia (enquanto quaisquer técnicas e/ou tecnologias de representação semiótico-midiáticas).

Ao situar o regime farmacopornográfico, Preciado o carrega de historicidade ao apontar que a farmacopornografia se intensificou a partir da Segunda Guerra Mundial, já sendo uma justaposição dos poderes soberano e disciplinar, levando a biopolítica foucaultiana ao limite de sua aplicabilidade.

Para remontar o plano de fundo em que surge a teoria de Preciado, Rucovsky retorna à sua caixa de ferramentas, que compreende a influência de Annie Sprinkle, Bruno Latour, Donna Haraway, Foucault, Karen Barad, Philippe Pignarre, Teresa Forcades i Vila, Teresa de Lauretis, Susan Kessler, entre outras, reconstruindo seus argumentos e, metodologicamente, supondo que a crítica preciadiana é, em alguma medida, mais precisa ou exata que a butleriana, tanto em sua descrição dos processos de materialização dos corpos quanto em sua demonstração da produção contemporânea de subjetividades.

Para Rucovsky (2016, p. 114), o projeto geral de Preciado, com a publicação de Manifesto Contrassexual (2000), seguida de Testo Yonqui (2008) e Pornotopía (2010), se trata de uma crítica analítica ao "feminismo construtivista" dos anos noventa, centrando-se na teoria performativa, sim, mas ao mesmo tempo desenvolvendo a sua própria tese, que nos chama a atenção para uma nova perspectiva epistemossexual. De modo similar a Butler, se vale de um amplo espectro conceitual, tendo em vista 
investigar a produção contemporânea de subjetividades, sustentando que a matriz heterossexual discursiva, que opera a inteligibilidade cultural, seria insuficiente para dar conta da "questão da tecnologia". Em outras palavras, estamos imersos em um regime de produção, reprodução e consumo de artefatos tecnológicos em uma ordem de excitação-frustração-excitação, operando de modo a manter os sujeitos híbridos por meio das próteses, isto é, por meio de dispositivos maleáveis e tragáveis que se dissolvem no corpo orgânico, rompendo e redefinindo os limites do que é humano e não humano.

Diferente de Butler, para Preciado o gênero é, antes de tudo, prostético, composto por códigos semiótico-materiais que produzem a carne tecnocientificamente. Partindo da figura do ciborgue, Preciado expande as suas análises da história da produção tecnológica da carne, dando um alcance ontológico a esta reflexão por meio de elementos como a estilística de Donna Haraway e a teoria do ator-rede, de Bruno Latour, para apontar os problemas implicados no consumo das próteses, que funcionam de modo integrado para fixar, com êxito, uma realidade material orgânica ao sexo e ao gênero.

Rucovsky questiona quais são os limites que definem e delimitam o corpo tecnossexuado de Preciado, enfatizando que para o filósofo a visão fenomenológica e construtivista de gênero fracassa em seus postulados, podendo resultar em uma renaturalização das identidades. Entretanto, este corpo produzido farmacopornograficamente, conectado e convertido em uma prótese cibernética pensante, que se inter-relaciona por meio de um sistema semiótico em rede, será o mesmo corpo que irá dinamitar o regime farmacopornográfico, de dentro para fora.

O quarto e último ato é intitulado com uma pergunta, qual seja, "os limites da carne coincidem com os limites do corpo?". Este é um espaço que Rucovsky projetou para analisar de que modo é possível desacreditar o que Judith Butler e Paul B. Preciado nos causaram, página atrás de página, em um sentido de apontar para possíveis caminhos e diferentes interpretações. Quer dizer, é aqui, precisamente, em que se dará a continuidade a uma reflexão que Mauro Cabral inicia no prólogo de Cuerpos en escena. Martín Rucovsky, Mauro Cabral e Blas Radi realizam um movimento que permite passar as teorias por seus próprios crivos e chamam este movimento de efeito bumerangue.

Rucovsky elenca três efeitos bumerangue, sendo o primeiro e o segundo intimamente relacionados, centrando-se em uma análise ético-metodológica a partir das crítica de Mauro Cabral acerca do uso acadêmico das vidas, corpos, identificações, histórias e práticas transviadas. Tanto Judith Butler quanto Paul B. Preciado utilizam, em seus corpora teóricos, da vida e história de pessoas travestis, transexuais, transgênero e intersexo, de Herculine e Venus Xtravaganza a Agnès e o próprio Preciado, ocorre uma apropriação e uma coletivização destes casos e testemunhos. Com o terceiro efeito bumerangue, Rucovsky sintetiza as críticas de Mauro Cabral, Blas Radi e Paula Viturro ao apontar o resultante problemático da apropriação e coletivização das vidas transviadas, pois são estudos e investigações que podem levar à objetificação e um apagamento das pessoas travesti, transexuais, transgênero e intersexo na medida em que se produzem, analisam e consomem estas histórias como em uma "canibalização acadêmica queer" (RUCOVSKY, 2016, p. 163).

Neste ato Rucovsky também aponta para algumas contradições na teoria preciadiana, uma vez que converter as pessoas trans na dinamite para fazer voar pelos ares o regime hegemônico heteronormativo faz com que a farmacopornografia, em alguma medida, também seja causadora de uma hegemonia, sobretudo quando Preciado intenta universalizar o alcance de suas hipóteses acerca do regime farmacopornográfico, ainda privilegiando secretamente uma visão tão eurocêntrica quanto hegemônica (2016, p. 166). Portanto, do ponto de vista decolonial e pós-colonial, presumir um efeito hegemônico e globalizado para a farmacopornografia pode facilmente cair no 
erro de, uma vez mais, fazer do norte global um ponto de referência que diferencia e exclui, por consequência, as corporalidades locais de cada contexto socio-histórico.

Em vias do fim, pensando alto com Eduardo Mattio e Virginia Cano, Rucovsky questiona-se como poderíamos abordar as singularidades dos corpos sem cair em uma inevitável generalização, bem como seria possível registrar estas singularidades e multiplicidades a que chamamos de "um corpo", em suas diferentes escalas e dimensões, tempos e espaços. A partir daí, Rucovsky afirma que apesar de todas as estratégias e escolhas metodológicas, as teorias de Judith Butler e Paul B. Preciado não são opostas, mas complementares, girando em torno da questão da (bio)tecnologia, que leva as narrativas da performatividade a um plano molecular de exercício do poder na produção da materialidade sexuada dos corpos prostéticos.

Como Preciado não se desfaz da teoria performativa, mas a adapta, podemos compreender que a performatividade é tão prostética quanto a prótese é performativa, de modo que não são teorias opositivas, mas complementares e, como diz Rucovsky (2016, p. 189), "a performance discursiva e a codificação textual do mundo são operações mais similares do que o seu próprio teatro de operações [de Preciado] está disposto a assumir".

Variando entre os graus de objetividade e subjetividade necessários para uma abordagem extensa como a que realizou, Rucovsky alcança seus objetivos em Cuerpos en escena, o que faz notável a sua contribuição. No Brasil, embora estejam ganhando visibilidade, as teorias de Butler e de Preciado ainda são pouco conhecidas se comparadas às de outras autoras e autores da filosofia. Os estudos de gênero e queer/cuir, como áreas de pesquisa, ainda estão se fundamentando. Neste cenário, a leitura da obra de Rucovsky pode ser considerada fundamental, pois nela se encontra um rico referencial teórico, além de comentários e reflexões originais. Esperamos que, com isso, Cuerpos en escena seja conhecido, divulgado e traduzido. Portanto, convidamos à leitura na íntegra e recomendamos a dedicação às análises de Rucovsky, que podem ser de grande valia nos repertórios pessoais de cada um, seja por curiosidade, estudo ou pesquisa, pois, sem dúvida, pode esclarecer e aprofundar as principais questões em torno de Judith Butler e Paul B. Preciado, sendo como uma planificação cartografada de suas teorias.

Correspondência: Bryan Axt. Pontifícia Universidade Católica do Paraná - PUC-PR. Escola de Educação e Humanidades. Departamento de Filosofia. Rua Imaculada Conceição, 1155. Prado Velho. Curitiba - PR Brasil. CEP: 80215-901. E-mail: bwaxtakh@gmail.com.

Apoio financeiro: Nenhum.

Conflito de interesses: Nenhum.

Todos os autores leram e aprovam a versão final submetida à revista Em curso.

Recebido em: 29/Mai/2018 - Aceito em: 10/Jul/2018. 